\title{
Evaluation of Serum Lipid Profile Level and Gamma- Glutamyltransferase Activity as a Biomarker for Coronary Artery Disease in Sudanese Patients
}

\author{
Osama M. Hussein ${ }^{1 *}$, Amar M. Ismail ${ }^{2}$, Omer F. Idris ${ }^{2}$ \\ ${ }^{1}$ Department of Microbiology and Molecular Biology, Faculty of Science and Technology, Al Neelain University, Khartoum, Sudan. \\ ${ }^{2}$ Department of Biochemistry and Molecular Biology, Faculty of Science and Technology, Al Neelain University, Khartoum, Sudan .
}

\begin{tabular}{|c|c|}
\hline ARTICLE INFO & ABSTRACT \\
\hline Article history: & \multirow{9}{*}{$\begin{array}{l}\text { Coronary artery disease (CAD) is a worldwide public health problem with high morbidity and mortality. There } \\
\text { is evidence from recent studies that Gamma-glutamyltransferase }(\gamma-\mathrm{GT}) \text { is likely to be associated with CAD. } \\
\text { However, no studies to date investigated the association of } \gamma \text {-GT with CAD in Sudanese patients. This study } \\
\text { aimed to assess the lipid profile level and } \gamma \text {-GT activity of Sudanese patients with CAD. A cross-sectional study } \\
\text { was performed in which } 60 \text { clinically diagnosed patients with CAD and } 60 \text { apparently healthy (control group) } \\
\text { were enrolled. Serum total cholesterol (TC), triglycerides (TG), high-density lipoprotein-cholesterol (HDL-C), } \\
\text { low-density lipoprotein-cholesterol (LDL-C) concentrations and } \gamma \text {-GT activity were measured. The commonest } \\
\text { lipid abnormalities in the patients were; reduced TG ( } 77 \%<150 \mathrm{mg} / \mathrm{dl}) \text { and HDL-C }(68 \% \leq 60 \mathrm{mg} / \mathrm{dl}) \text { and } \\
\text { increased TC, LDL-C and } \gamma \text {-GT in men and women }(80 \%>200 \mathrm{mg} / \mathrm{dl}, 72 \%>130 \mathrm{mg} / \mathrm{dl} \text { and }>22 \mathrm{U} / 1 \\
\text { respectively). Statistically significant (P } \leq 0.05) \text { increases were present in the TC, TG, LDL-C and } \gamma \text {-GT } \\
\text { concentrations between the case and the control group. However, the patients showed a statistically significant } \\
\text { decrease in HDL-C concentration compared to the control group. These findings suggest that dyslipidemia is } \\
\text { common among Sudanese patients with CAD and } \gamma \text {-GT could be used as a biomarker to CAD. }\end{array}$} \\
\hline Received on: 10/12/2016 & \\
\hline Accepted on: 12/03/2017 & \\
\hline Available online: $30 / 10 / 2017$ & \\
\hline Key words: & \\
\hline Coronary artery disease & \\
\hline (CAD). Gamma- & \\
\hline glutamyltransferase $(\gamma-\mathrm{GT})$. & \\
\hline Lipid profile. & \\
\hline
\end{tabular}

\section{INTRODUCTION}

Coronary artery disease (CAD) is a leading cause of death in the developed and developing countries (Roeters van Lennep et al., 2002; Han et al., 2014; Mao et al., 2014; Zhang et al., 2014). Coronary arteriosclerosis comprises a series of inflammatory responses at cellular and molecular level (Gomes et al., 2010). It is a chronic inflammatory disease affecting blood vessels, in which the arterial wall thickens because of the formation of an atheromatous plaque (De Paoli et al., 2014).

\footnotetext{
* Corresponding Author

Osama M. Hussein, Department of Microbiology and Molecular Biology, Faculty of Science and Technology, Al Neelain University, Khartoum, Sudan. E-mail: osamamicro123 @ gmail.com, Mobile: 00249912117979
}

The early stages of atherogenesis are characterized by infiltration of monocytes in the sub-endothelium and their differentiation into macrophages. Macrophages clear the excess modified lipoproteins that accumulate in the neointima and as a consequence, the macrophages become engorged with lipids and can no longer emigrate from the plaque (De Paoli et al., 2014).

Risk factors for coronary artery disease have included high blood pressure, cigarette smoking, increased low-density lipoprotein concentration, decreased high-density lipoprotein concentration, and diabetes (Homoud, 2008). Factors such as obesity, left ventricular hypertrophy and family history of premature CAD have also been considered in defining CAD (Wilson et al., 1998). Elevated plasma levels of endothelial markers, such as von Willebrand factor, and soluble vascular cell adhesion molecule-1 may serve as molecular markers for atherosclerosis (Alvares-daSilva et al., 2014). 
The gold-standard technique for the diagnosis of CAD is coronary angiography. However, new techniques have been introduced such as coronary computed tomography angiography and magnetic resonance imaging which are more sensitive and noninvasive (Allajbeu et al., 2014). Gamma-glutamyltransferase $(\gamma-\mathrm{GT})$ has long been used as a marker of excessive alcohol intake. Gamma-GT is located on plasma membranes of several cells and tissues with a predominance of hepatocytes. Recent studies showed that increased serum $\gamma$-GT activity could be used as a marker for increased oxidative stress in humans.

Several population-based studies have found positive associations of $\gamma$-GT with incident cardiovascular events. Yet the magnitude of associations differs between studies, and no such study was conducted in Sudanese patients.

This study aimed to elucidate the relationship of serum $\gamma$ GT activity and CAD in Sudanese patients and its potential to be used as a biomarker for CAD and to investigate the differences in serum level of $\gamma$-GT, total cholesterol (TC), triglyceride (TG), high-density lipoprotein-cholesterol (HDL-C) and low-density lipoprotein-cholesterol (LDL-C) in patients suffering from CAD and healthy individuals.

\section{MATERIALS AND METHODS}

\section{Study Area and Study Population}

This study was conducted in Sudan Heart Centre (SHC), Khartoum State - Sudan during the period from May to August 2014. The study included adult patients who had undergone coronary angiography at the SHC. A total of 120 participants were enrolled in the study, which consisted of 60 clinically diagnosed patients (CAD group) and 60 normal participants (control group).

\section{Study Design}

A case-control study was conducted, in which the patients were gathered using questionnaires containing participant age, gender, residence and the medical history.

All subjects were asked to provide information about cardiovascular risk factors such as hypertension or diabetes mellitus, smoking, and details regarding any medication received before the admission. Subjects were considered to have diabetes or hypertension if they had been informed of the diagnosis by a physician, taking oral anti-hyperglycemic agents or insulin or blood pressure lowering treatment. Subjects were considered as smokers if they smoked at the time of admission.

\section{Sampling Criteria}

Patients with any of the following clinical condition(s) were excluded from the study: 1) Liver disease or kidney disease 2) Severe infections or heart failure 3) Hyperthyroidism, hypothyroidism, cancer, autoimmune diseases, or chronic connective tissue disease 4) Major surgery, trauma, or burns.

\section{Ethical Consideration}

The study protocol was approved by the local ethics committee at the SHC and written and verbal consent was obtained from all subjects enrolled in the study.

\section{Sample Collection}

Venous blood samples were collected from 60 patients based on their stratification at the SHC and 60 apparently healthy individuals using sterile syringe in plain blood containers and centrifuged for 5 minutes at 4000 r.p.m. The resultant sera were transferred into new plain containers and stored at $-20^{\circ} \mathrm{C}$ until used.

\section{Determination of TC, TG, HDL-C and LDL-C Concentrations and $\gamma$-GT Activity}

Total cholesterol, TG, HDL-C and LDL-C concentrations along with $\gamma$-GT activity were measured using BioSystem S.A. Costa Brava 30, 08030 Barcelona (Spain) kits.

\section{Statistical Analysis}

A statistical analysis was performed using SPSS version 16.0 software for Windows (SPSS, Inc., Chicago, IL, USA) and Microsoft Office Excel 2007. The descriptive statistics performed include; mean, median, standard deviation (S.D.), minimum, maximum, frequency and percentage. Data were presented as mean \pm S.D. and median (minimum - maximum), as appropriate. Categorical variables were reported as frequencies and group percentages.

Independent sample $t$ test and one-way ANOVA test were performed to test whether there are statistically significant differences between the patients and the normal participants in $\mathrm{TC}$, TG, HDL-C, LDL-C concentrations and $\gamma$-GT activity. All values of $\mathrm{P} \leq 0.05$ were considered to indicate statistically significant differences between the tested groups. Pearson's correlation was performed to evaluate whether there is a positive or negative correlation between the tested parameters.

\section{RESULTS}

\section{Description of the Study Population}

In the study population $69(57.5 \%)$ subjects were male and $51(42.5 \%)$ were female. The mean \pm S.D. of the male ages was $55.86 \pm 1.3$ and the median (minimum - maximum) was 56 $(32-80)$ years old. Whereas, the mean \pm S.D. of the female ages was $61.675 \pm 1.3$ and the median (minimum - maximum) was 53 $(26-79)$ years old. The male and the female within the case and the control group are shown in table 1.

The medical history of the patients is shown in fig. 1 . 
Table 1: The number and the percentages of male and female in the case and the control groups.

\begin{tabular}{|c|c|c|c|c|}
\hline & & \multirow{2}{*}{ Number } & \multicolumn{2}{|c|}{ Age } \\
\hline & & & Mean \pm S.D. & Median (min. - max.) \\
\hline \multirow{2}{*}{ Case $(n=60)$} & Male & $35(58 \%)$ & \multirow{2}{*}{$58.9 \pm 12.4$} & \multirow{2}{*}{$60(30-80)$} \\
\hline & Female & $25(42 \%)$ & & \\
\hline Control $(n=60)$ & Male & $34(57 \%)$ & $44.2 \pm 9$ & $43(26-65)$ \\
\hline
\end{tabular}

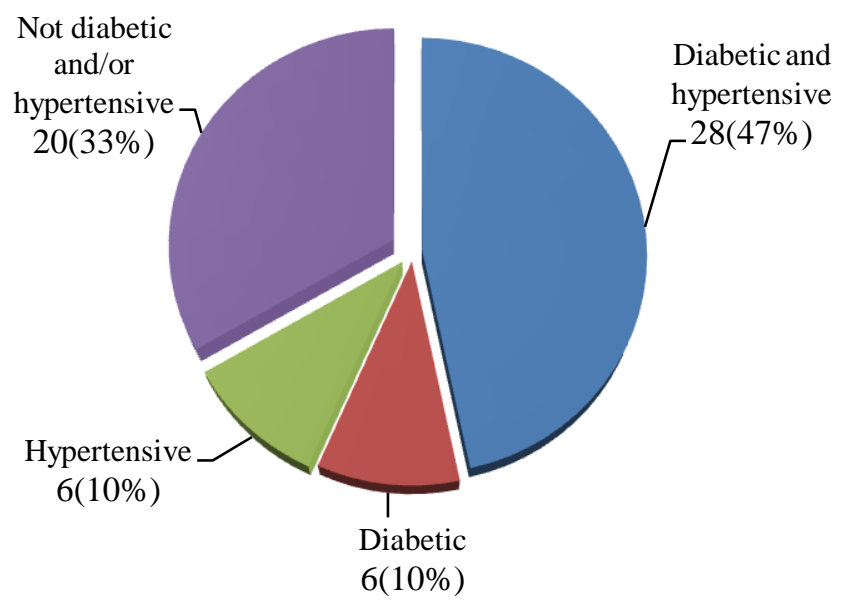

Fig. 1: The medical history of the patients.

Table 2: Frequency of study parameters classified based on reference range within male and female suffering from CAD

\begin{tabular}{|c|c|c|c|c|}
\hline Parameter & Reference Value & $\begin{array}{cl} & \text { Male } \\
\text { Count (\% } & \text { Within Gender) }\end{array}$ & $\begin{array}{c}\text { Female } \\
\text { Count }(\% \text { Within Gender })\end{array}$ & Total $(\%)$ \\
\hline \multirow{4}{*}{$T C$} & $\leq 200 \mathrm{mg} / \mathrm{dl}$ Desirable & $7(20 \%)$ & $5(20 \%)$ & $12(20 \%)$ \\
\hline & $200-239 \mathrm{mg} / \mathrm{dl}$ Borderline High & $15(43 \%)$ & $9(36 \%)$ & $24(40 \%)$ \\
\hline & $>240 \mathrm{mg} / \mathrm{dl} \mathrm{High}$ & $13(37 \%)$ & $11(44 \%)$ & $24(40 \%)$ \\
\hline & Total $(\%)$ & $35(100 \%)$ & $25(100 \%)$ & $60(100 \%)$ \\
\hline \multirow{4}{*}{$T G$} & $<150 \mathrm{mg} / \mathrm{dl}$ Normal & $26(74 \%)$ & $20(80 \%)$ & $46(77 \%)$ \\
\hline & 150-199 mg/dl Borderline High & $7(20 \%)$ & $1(4 \%)$ & $8(13 \%)$ \\
\hline & $200-244 \mathrm{mg} / \mathrm{dl}$ High & $2(6 \%)$ & $4(16 \%)$ & $6(10 \%)$ \\
\hline & Total $(\%)$ & $35(100 \%)$ & $25(100 \%)$ & $60(100 \%)$ \\
\hline \multirow{3}{*}{$H D L-C$} & $\leq 60 \mathrm{mg} / \mathrm{dl}$ Low & $23(66 \%)$ & $18(72 \%)$ & $41(68 \%)$ \\
\hline & $>60 \mathrm{mg} / \mathrm{dl}$ Normal & $12(34 \%)$ & $7(28 \%)$ & $19(32 \%)$ \\
\hline & Total $(\%)$ & $35(100 \%)$ & $25(100 \%)$ & $60(100 \%)$ \\
\hline \multirow{3}{*}{$L D L-C$} & $<130 \mathrm{mg} / \mathrm{dl}$ Normal & $12(34 \%)$ & $5(20 \%)$ & $17(28 \%)$ \\
\hline & $>130$ mg/dl High & $23(66 \%)$ & $20(80 \%)$ & $43(72 \%)$ \\
\hline & Total $(\%)$ & $35(100 \%)$ & $25(100 \%)$ & $60(100 \%)$ \\
\hline \multirow{3}{*}{$\gamma-G T$} & & $<22 \mathrm{mg} / \mathrm{dl}$ Normal $13(37 \%)$ & $<15 \mathrm{mg} / \mathrm{dl}$ Normal $4(16 \%)$ & $17(28 \%)$ \\
\hline & & $>22 \mathrm{mg} / \mathrm{dl}$ High $22(63 \%)$ & $>15$ mg/dl High $21(84 \%)$ & $43(72 \%)$ \\
\hline & Total (\%) & $35(100 \%)$ & $25(100 \%)$ & $60(100 \%)$ \\
\hline
\end{tabular}

\section{Description of the Tested Parameters}

The mean concentration of TC mg/dl, TG mg/dl, HDL-C $\mathrm{mg} / \mathrm{dl}$, LDL-C $\mathrm{mg} / \mathrm{dl}$ and $\gamma-\mathrm{GT} \mathrm{U} / \mathrm{l}$ in the study population are shown in fig. 2. Independent sample $t$ test was conducted to test whether there is a statistically significant difference $(\mathrm{P}<0.05)$ between the case and the control group in the measured parameters and if serum $\gamma$-GT can be used as a biomarker for CAD.

The independent $t$ test analysis showed a statistically significant increase of TC, TG, LDL-C and $\gamma$-GT between the case and the control group $(\mathrm{P}<0.05)$. However, a significant decrease was observed in the HDL-C concentration $(\mathrm{P}=0.004)$ as shown in fig. 2. The results were also confirmed using One-Way ANOVA test.

The distribution of the male and the female with CAD within the reference value are shown in table 3. For the TC (mg/dl), $7(20 \%)$ and $5(20 \%)$ of the male and the female respectively (column 3 and 4 in table 2) showed a desirable level of TC. However, $24(40 \%)$ of the male and the female showed borderline high level and $24(40 \%)$ of them showed high level (column 5 in table 2). 
Table 3: The mean levels of TC, TG, HDL-C, LDL-C and $\gamma$-GT in the male and the female patients suffering from CAD.

\begin{tabular}{|c|c|c|c|}
\hline Parameter & $\begin{array}{c}\text { Male } \\
\text { Mean } \pm \text { S.D. }\end{array}$ & $\begin{array}{c}\text { Female } \\
\text { Mean } \pm \text { S.D. }\end{array}$ & P-value \\
\hline TC mg/dl & $230.1 \pm 42.5$ & $231.6 \pm 41.3$ & 0.888 \\
\hline$T G \mathrm{mg} / \mathrm{dl}$ & $100.1 \pm 53.1$ & $115.4 \pm 53.2$ & 0.275 \\
\hline$H D L-C m g / d l$ & $58.5 \pm 40.6$ & $54.0 \pm 22.1$ & 0.616 \\
\hline$L D L-C m g / d l$ & $151.6 \pm 47.0$ & $154.6 \pm 48.0$ & 0.810 \\
\hline$\gamma-G T U / l$ & $25.7 \pm 14.1$ & $28.0 \pm 13.2$ & 0.535 \\
\hline
\end{tabular}

* Statistically significant difference $(P \leq 0.05)$, result expressed as mean \pm S.D.
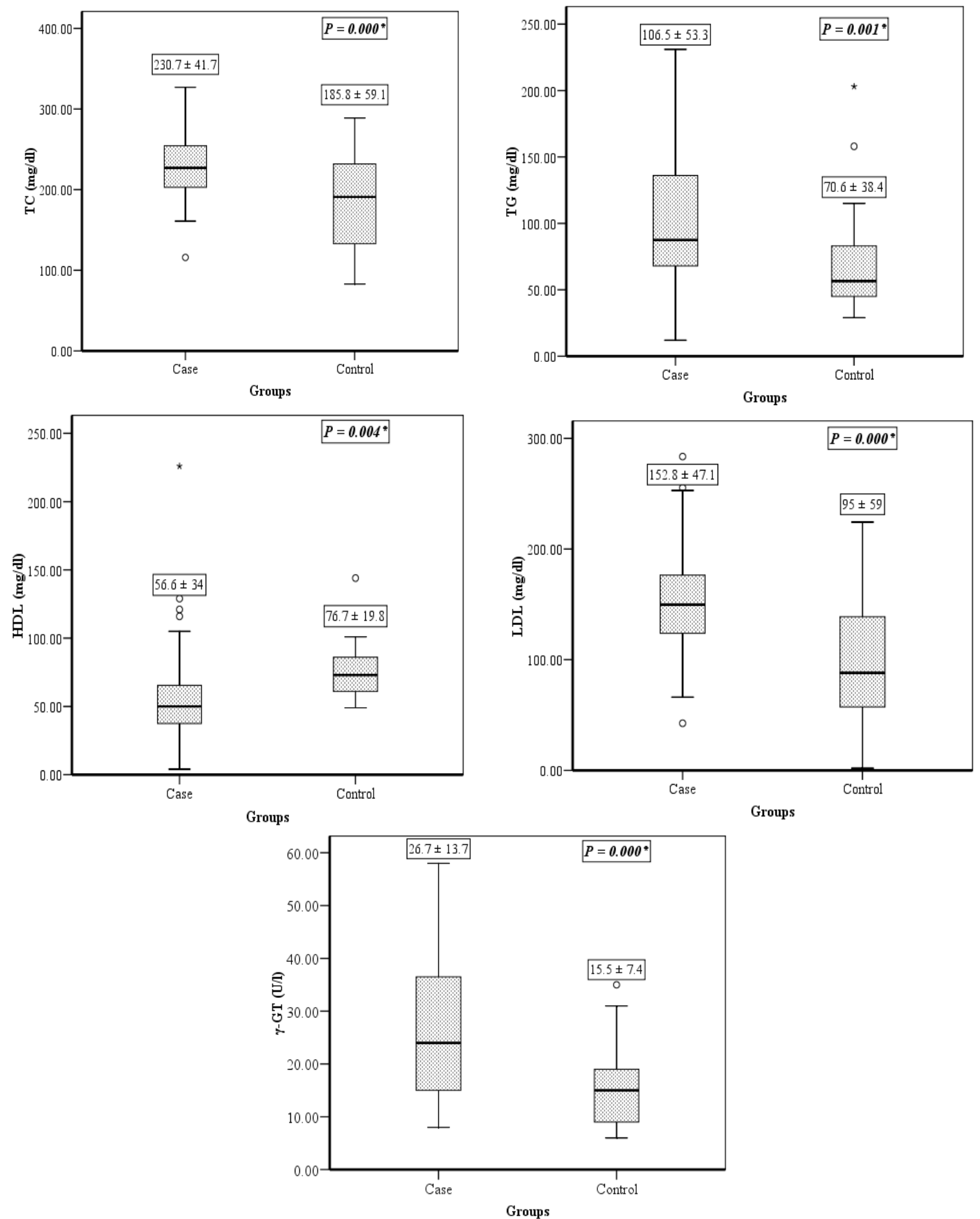

Fig. 2: Mean TC, TG, HDL-C, LDL-C and $\gamma$-GT in the case and the control group

* Statistical significant difference $(P<0.05)$, result expressed as mean \pm S.D 

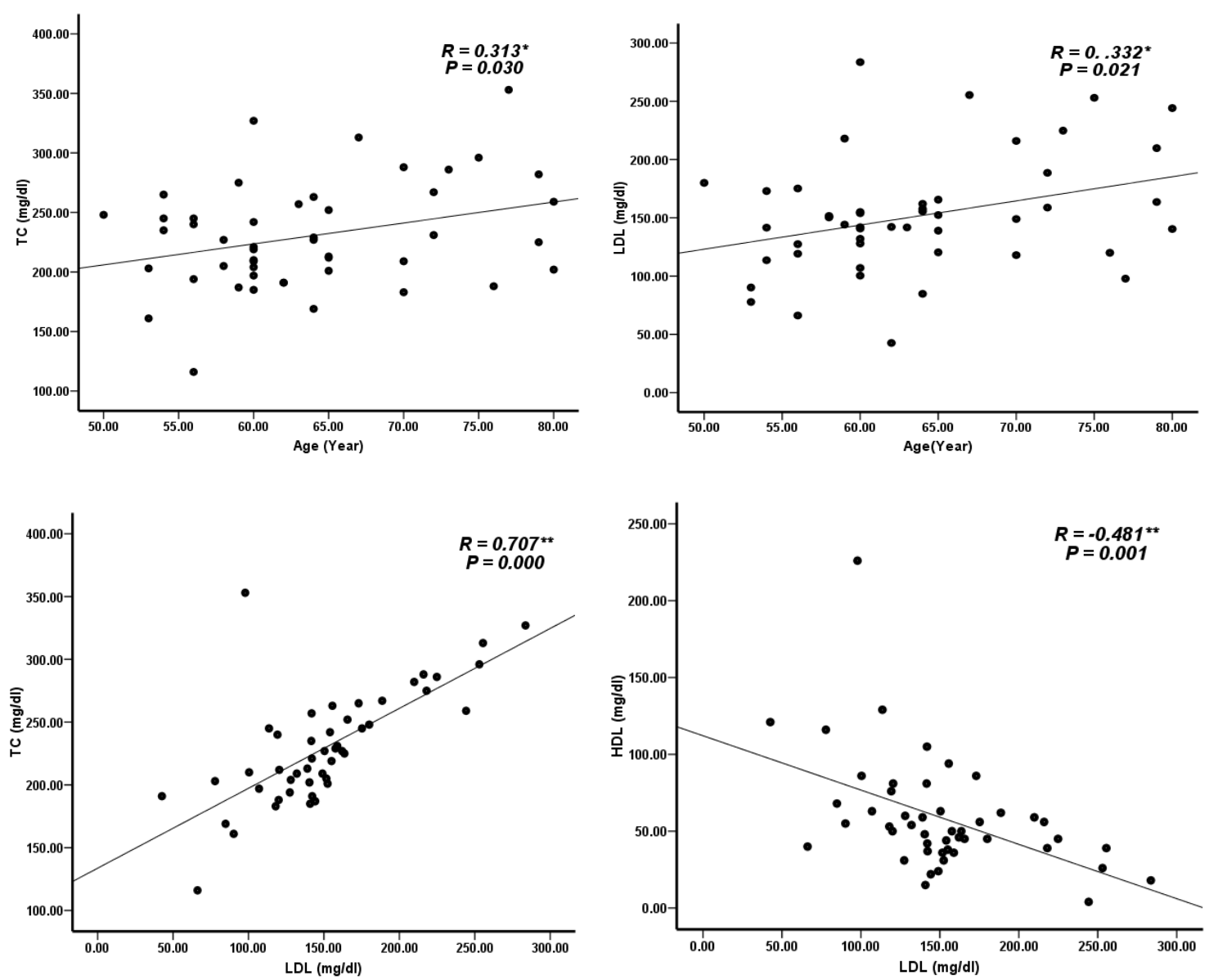

Fig. 3: Dot plot association between a) age and TC, b) age and LDL-C c) LDL-C and TC, d) LDL-C and HDL-CTC in patients $\geq 50$ years suffering from CAD. * corelation is significant at 0.05 level., ** correlation is significant at 0.01 level., $\mathrm{R}=$ negative or positive correlation., $\mathrm{P}=$ strength of correlation

\section{DISCUSSION}

It is well known that atherosclerosis is a multifocal, chronic immunoinflammatory disease whose pathogenesis involves imbalanced lipid metabolism and a maladaptive immune response, in which endothelial cells, leukocytes and intimal smooth muscle cells are the major cellular players (Zhu et al., 2014).

In the present study, a total of 60 patients suffering from CAD diagnosed using coronary angiography were compared with 60 normal individuals. Those patients were diagnosed with a single-vessel disease (SVD), double-vessels disease (DVD) or triple-vessels disease (TVD). Overall, it is clear that $77 \%$ of the patients have a medical history of diabetes mellitus, hypertension or both and around $65 \%$ of them have no family history of CAD. On the other hand, $50 \%$ of the control group reported no family history of hypertension, diabetes mellitus and/or CAD. Some studies have found that most CAD patients have a family history of $\mathrm{CAD}$ and that genetic factors play an important role in the incidence of CAD. However, the genetic risk factors of CAD have not been fully determined (Zhang et al., 2014). Epidemiological studies consistently demonstrated that certain risk factors serve as contributing factors to increased risk of CAD at an individual level (Rydèn et al., 2007). These risk factors include: arterial high blood pressure, diabetes mellitus, dyslipidemias, metabolic syndrome, (Homoud, 2008; Gomes et al., 2010) and factors linked to unhealthy lifestyles such as unhealthy eating habits, physical inactivity, overweight/abdominal obesity, smoking and family history of premature CAD (Rydèn et al., 2007; Homoud, 2008).

In the present study, the mean \pm S.D. of the TC in the patients were found to be higher than the normal reference value. A statistically significant difference was found between the patient and the control group $(\mathrm{P}=0.000)$. Moreover, there was a significant and positive correlation between $\mathrm{TC}$ concentration and patient's age ( $>50$ years) $(\mathrm{P}=0.030 \mathrm{R}=0.0313)$. In a study conducted by Mao et al. (2014) the mean \pm S.D. of the TC in patients with single, double, and triple vessels disease were $4.61 \pm$ $0.93,4.73 \pm 1.12$ and $4.66 \pm 1.24 \mathrm{mmol} / \mathrm{l}$ respectively. Another study conducted by Haddad et al. (2002) showed $231.43 \pm 57.99$ $\mathrm{mg} / \mathrm{dl}$ in consistent with our current results. Increased TC values are associated with a progressively escalating risk of atherosclerosis and CAD (Bahia et al., 1999). The triglycerides concentration in the patients were found to be within the desirable range (up to $150 \mathrm{mg} / \mathrm{dl}=1.7 \mathrm{mmol} / \mathrm{l}$ ), however, a statistically 
significant difference was found between the patient and the control group $(\mathrm{P}=0.001)$. In a study conducted by Haddad et al. (2002), the TG concentration in the patients was $246.95 \pm 142.1$ $\mathrm{mg} / \mathrm{dl}$ which is higher than our value. However, our result was closer to the results found by Mao et al. (2014) $(1.6 \pm 0.95 \mathrm{mmol} / \mathrm{l}$ in the patients with SVD, $1.85 \pm 1.49 \mathrm{mmol} / \mathrm{l}$ in the patients with DVD and $1.79 \pm 1.3 \mathrm{mmol} / \mathrm{l}$ in the patients with TVD).

High-density lipoprotein in the patients showed decreased concentration in comparison with the reference values (> $60 \mathrm{mg} / \mathrm{dl}=0.91 \mathrm{mmol} / \mathrm{l}$ ), however, the control group showed a normal HDL-C concentration $(76.7 \pm 19.8 \mathrm{mg} / \mathrm{dl})$. In contrast to the results found by Haddad et al. (2002) in which HDL-C in the patients and the control group were found to be lower than the reference value $(35.98 \pm 9.37$ and $44.43 \pm 8.34 \mathrm{mg} / \mathrm{dl}$ respectively). Mao et al. (2014) showed that the concentration is higher in the control group $(1.09 \pm 0.3 \mathrm{mmol} / \mathrm{l})$ followed by the patients with SVD, DVD and TVD. High-density lipoprotein plays an important part in the removal of cholesterol from tissue and its transportation to the liver for removal as bile acids. Decreased plasma HDL-C concentration is positively correlated with the incidence of atherosclerosis disease (Bahia et al., 1999). It has been demonstrated that HDL-C possesses significant antioxidant activity, primarily mediated via the inhibition of the ox-LDL with a subsequent reduction of the cellular uptake by the monocyte macrophage system. In addition, HDL-C could prevent atherosclerosis via effects on platelet function, endothelial function, coagulation parameters, inflammation, and interactions with triglyceride-rich lipoprotein (Mao et al., 2014).

Patient's LDL-C concentration was found to be higher than the normal range $(<130 \mathrm{mg} / \mathrm{dl})$. The patients and the control group showed a statistically significant difference by increase in serum LDL-C concentration $(\mathrm{P}=0.000)$. At the same time increased LDL-C concentration was significantly and positively correlated with increased age $(\mathrm{R}=0.332, \mathrm{P}=0.021)$. Moreover, a significant and strong negative correlation was found between LDL-C and HDL-C ( $R=-0.481, P=0.001)$ however, a significant and fairly strong positive correlation was found between LDL-C and TC concentrations $(\mathrm{R}=0.707, \quad \mathrm{P}=0.000)$. Low-density lipoprotein cholesterol is known as the "bad" cholesterol because too much LDL-C in the blood is associated with blockage of the arteries in the heart (Bahia et al., 1999).

The mean concentration of $\gamma$-GT was found to be significantly higher $(\mathrm{P}=0.000)$ in the patients in comparison with the control group $(26.7 \pm 13.7$ and $15.5 \pm 7.4$ respectively). In the same line, Mao et al. (2014), showed that serum $\gamma$-GT levels were higher in patients with TVD and DVD in comparison with the control group and the patients with a SVD (Mao et al., 2014). Gamma-GT is an enzyme on the surface of the cellular membrane, which is responsible for the extracellular catabolism of glutathione of the anti-oxidation mechanism (Demircan et al., 2013). Ectoplasmic $\gamma$-GT has been implicated in the generation of reactive oxygen species, and consistent evidence supports its role as a marker of systemic oxidative stress. Gamma-GT levels were first associated with cardiovascular disease and all-cause mortality in a British Regional Heart Study by Wannamethee reported in October of 1995. This study evaluated 7613 British men over 11.5 years in England, Wales and Scotland (Mason et al., 2010). In a study conducted by Emdin et al. (2001), serum $\gamma$-GT level was found to be associated with cardiac death and non-fatal MI in patients with documented CAD. Another study by Lee and Jacobs (2005), report an association between serum levels of $\gamma$-GT and Creactive protein (CRP) and $\gamma$-GT as a marker of low-grade systemic inflammation.

According to a prospective study of 6997 subjects (aged 40-59 years) with no history of CAD or diabetes mellitus in 24 British towns, researchers performed a 24-year followed-up and concluded that the elevated $\gamma$-GT $(\geq 22 \mathrm{U} / \mathrm{L})$ was significantly related to the increased risk of fatal CAD events and mortality (Fraser et al., 2007). The possible mechanisms of serum $\gamma$-GT as a marker of inflammation might be; 1) $\gamma$-GT might promote atherogenesis by binding to LDL-C particles, 2) $\gamma$-GT has been found in atherosclerotic plaques, 3) Higher serum $\gamma$-GT is associated with an increased incidence of the metabolic syndrome, 4) Higher serum $\gamma$-GT is associated with oxidative stress which may promote atherogenesis (Fraser et al., 2007).

In the light of these studies, many epidemiologic studies investigated the value of serum $\gamma$-GT level in predicting the development of CVD, mortality from all causes including MI, stroke and cardiac death. Ulus et al. (2008) found that high serum $\gamma$-GT level is an independent and better predictor than CRP for the development of major cardiovascular event in patients with acute coronary syndromes over 1 and 6 month follow-up periods and found a positive correlation between serum CRP and $\gamma$-GT levels (Ulus et al., 2008). In a study conducted by Mason et al. (2010), serum $\gamma$-GT levels were found to be related to alcohol intake, coronary lesion count, TG, HDL-C, and age in the CAD group.

In the same line, Stojakovic et al. (2010) investigated the relationship between $\gamma$-GT and total as well as cardiovascular mortality in 2556 subjects with and 699 subjects without angiographic evidence of CAD. They showed that serum $\gamma$-GT predicts all-cause and cardiovascular mortality in individuals with CAD independently of other cardiovascular risk factors.

\section{CONCLUSION}

This study was designed to investigate the differences in serum TC, TG, HDL-C, LDL-C and $\gamma$-GT levels in 60 patients suffering from $\mathrm{CAD}$ and 60 apparently normal individuals. The independent sample $t$ test showed a statistically significant difference in all the tested parameters $(\mathrm{P} \leq 0.05)$ between the case and the control group. The patient's group showed dyslipidaemia (elevated levels of serum TC, LDL-C and low levels of HDL-C). These findings suggest that $\gamma$-GT will be an important component of future biomarker and multimarker approaches to cardiovascular risk evaluation. However, further investigation of $\gamma$-GT will provide insights into the pathogenesis of CAD and better define the clinical utility of this marker. 


\section{AUTHOR CONTRIBUTIONS}

Conceived and designed the experiments: Osama M. Hussein. Supervised by: Omer F. Idris. Performed the experiments: Osama M. Hussein. Analyzed the data: Osama M. Hussein and Amar M. Ismail. Wrote the paper: Osama M. Hussein. Revised by: Amar M. Ismail and Omer F. Idris.

\section{ACKNOWLEDGEMENT}

The authors would like to acknowledge the donors, their families and the staff at $\mathrm{SCH}$ for their participation in this study. We also express our thanks to Ismail Mohamed Ismail for statistical analysis guidance.

\section{Financial support and sponsorship: Nil.}

Conflict of Interests: There are no conflicts of interest.

\section{REFERENCES}

Allajbeu, I., Hajro, E., Temali, I., Cekrezi, B. and Preza, K. The Role of CT Angiography of Coronaries in Early Diagnosis of Coronary Artery Plaques in Albanian People with No History of Cardiovascular Disease in Correlation with Traditional Risk Factors. Mater Sociomed, 2014; 26(3): 163-167.

Alvares-da-Silva, M.R., de Oliveira, C.P.M.S., Stefano, J.T., Barbeiro, H.V., Barbeiro, D., Soriano, F.G., Farias, A.Q., Carrilho, F.J. and Carneiro D'Albuquerque, L.A. Pro-atherosclerotic markers and cardiovascular risk factors one year after liver transplantation. World $J$ Gastroenterol, 2014; 20(26): 8667-8673.

Bahia, L., Gomes, M.B., da Cruz, P.M., Gonçalves, M.F. and Ernesto, P. Coronary Artery Disease, Microalbuminuria and Lipid Profile in Patients with Non-Insulin Dependent Diabetes Mellitus. Arq Bras Cardiol, 1999; 73(1): 17-22.

De Paoli, F., Staels, B. and Chinetti-Gbaguidi, G. Macrophage Phenotypes and Their Modulation in Atherosclerosis. Circulation Journal, 2014; 78(8): 1775-1781.

Demircan, S., Meric, M., Demir, S., Yuksel, S., Gulel, O., Zengin, H. and Soylu, K. Association of gamma-glutamyl transferase activity with coronary risk factors. Exp Clin Cardiol, 2013; 1-3.

Emdin, M., Passino, C., Michelassi, C., Titta F, L'abbate A, Donato L, Pompella A, Paolicchi A. Prognostic value of serum gammaglutamyl transferase activity after myocardial infarction. Eur Heart J, 2001; 22(19):1802-7.

Fraser, A., Harris, R., Sattar, N., Ebrahim, S., Smith, G.D. and Lawlor, D.A. Gamma-Glutamyltransferase Is Associated With Incident Vascular Events Independently of Alcohol Intake: Analysis of the British Women's Heart and Health Study and Meta-Analysis. Arterioscler Thromb Vasc Biol, 2007; 27: 2729-2735.

Gomes, F., Telo, D.F., Souza, H.P., Nicolau, J.C., Halpern, A. and Jr. C.V.S. Obesity and Coronary Artery Disease: Role of Vascular Inflammation. Arq Bras Cardiol, 2010; 94(2): 255-261.

Haddad, F.H., Omari, A.A., Shamailah, Q.M., Malkawi, O.M., Shehab, A.I., Mudabber, H.K. and Shubaki, M.K. Lipid profile in patients with coronary artery disease. Saudi Med J, 2002; 23(9): 1054-1058.
Han, X., Zhang, L., Zhang, Z., Zengtang, Zhang, Wang, J., Yang, J. and Niu, J. Association between Phosphatase Related Gene Variants and Coronary Artery Disease: Case-Control Study and MetaAnalysis. International Journal of Molecular Sciences, 2014; 15(8): 14058-14076.

Homoud M.K. Coronary Artery Disease. Tufts-New England Medical Center, pp: 2008; 1-13.

Lee, D.H. and Jacobs, D.R. Association between serum gammaglutamyltransferase and C-reactive protein. Atherosclerosis, 2005; 178: $327 \mathrm{e} 30$.

Mao, Y., Qi, X., Xu, W., Song, H., Xu, M., Ma, W. and Zhou, L. Serum gamma-glutamyl transferase: A novel biomarker for coronary artery disease. Med Sci Monit, 2014; 20: 706-710.

Mason, J.E., Starke, R.D. and Van Kirk, J.E. Gamma-Glutamyl Transferase : A Novel Cardiovascular Risk BioMarker. Preventive Cardiology, 2010; Winter 2010, pp.36-41. doi: 10.1111/j.17517141.2009.00054.x

Roeters van Lennep, J.E., Westerveld, H.T., Erkelens, D.W. and van der Wall, E.E. Risk factors for coronary heart disease: implications of gender. Cardiovascular Research, 2002; 53(3): 538-549.

Rydèn, L., Standl, E., Bartnik, M., Van den Berghe, G., Betteridge, J., de Boer, M-J., Cosentino, F., Jönsson, B., Laakso, M., Malmberg, K., Priori, S., Östergren, J., Tuomilehto, J. and Thrainsdottir, I. The Task Force on Diabetes and Cardiovascular Diseases of the European Society of Cardiology (ESC) and of the European Association for the Study of Diabetes (EASD). European Heart Journal, 2007; doi:10.1093/eurheartj/ehl261.

Stojakovic, T., Scharnagl, H., Trauner, M., Pieske, B., Wellnitz, B., Seelhorst, U., Schilling, D., Winkelmann, B.R., Boehm, B.O. and März, W. Serum gamma-glutamyl transferase and mortality in persons undergoing coronary angiography-The Ludwigshafen Risk and Cardiovascular Health Study. Atherosclerosis, 2010; 208(2): 564-571.

Ulus, T., Yildirir, A., Sade, L.E., Temiz, A., Polat, E., Bozbaş, H., Aydinalp, A., Eroğlu, S., Ozin, B. and Müderrisoğlu, H. Serum gamma-glutamyl transferase activity: new high-risk criteria in acute coronary syndrome patients? Coron Artery Dis, 2008; 19(7): :489-95.

Wilson, P.W.F., D’Agostino, R.B., Levy, D., Belanger, A.M., Silbershatz, H. and Kannel, W.B. Prediction of Coronary Heart Disease Using Risk Factor Categories. American Heart Association Circulation, 1998; 97: 1837-1847.

Zhang, Y., Ling, Z.Y., Deng, S.B., Du, H.A., Yin, Y.H., Yuan, J., She, Q., and Chen, Y.Q. Associations between CD36 gene polymorphisms and susceptibility to coronary artery heart disease. Brazilian Journal of Medical and Biological Research, 2014; 47(10): 895903. http://dx.doi.org/10.1590/1414-431X20143825 ISSN.

Zhu, F., Li, C., Jin, X-P., Weng, S-X., Fan, L-L., Zheng, Z., Li, W-L., Wang, F., Wang, W-F., Hu, X-F., Lv, C-L. and Liu, P. Celastrol may have an anti-atherosclerosis effect in a rabbit experimental carotid atherosclerosis model. Int J Clin Exp Med, 2014; 7(7):1684-1691.

\section{How to cite this article:}

Hussein OM, Ismail AM, Idris OF. Evaluation of Serum Lipid Profile Level and Gamma-Glutamyltransferase Activity as a Biomarker for Coronary Artery Disease in Sudanese Patients. J App Pharm Sci, 2017; 7 (10): 016-022. 